\title{
PENDAMPINGAN ADIK ASUH PUTUS SEKOLAH OLEH KAKAK ASUH PROGRAM PENDAMPINGAN CAMPUS SOCIAL RESPONSIBILITY (CSR) DINAS SOSIAL KOTA SURABAYA
}

\author{
Eko Sugandi ${ }^{1)}$, Tri Nuning Suhartatik ${ }^{2}$ \\ ${ }^{1}$ Fakultas Keguruan dan Ilmu Pendidikan, Universitas PGRI Adi Buana Surabaya \\ ${ }^{2}$ Fakultas Ekonomi, Universitas PGRI Adi Buana Surabaya \\ Email: ${ }^{1}$ __gandi@unipasby.ac.id, ${ }^{2}$ trinuningsuhartatik@gmail.com
}

\begin{abstract}
Abstrak
Campus Sosial Responsibility (CSR) Dinas Sosial Kota Surabaya merupakan program pendampingan anak putus sekolah dan anak rentan putus sekolah agar dapat kembali bersekolah. Banyak faktor yang mendasari terciptanya anak putus sekolah dan anak rentan putus sekolah diantaranya faktor ekonomi, rendahnya kepedulian orang tua terhadap pendidikan anak, dan kondisi lingkungan tempat tinggal yang kurang mendukung. Pelaksanaan program tersebut dilakukan dengan cara observasi, wawancara, dan dokumentasi dengan tujuan untuk mendapatkan informasi yang akurat dan terciptanya solusi yang efektif terhadap segala permasalahan yang dihadapi oleh adik asuh. Hasil yang didapatkan, dampaknya sangat baik terhadap perubahan baik dari segi sikap dan motivasi. Adik asuh dapat kembali bersekolah melalui jalur PKBM, lebih berani untuk mengungkapkan pemikiranya, lebih berani tampil di depan khalayak umum, dan lebih termotivasi untuk semakin giat belajar.
\end{abstract}

Kata Kunci: Pendampingan, adik asuh, putus sekolah, Campus Social Responsibility

\begin{abstract}
Campus Social Responsibility (CSR) Surabaya City Social Service is a mentoring program for dropouts and vulnerable children to drop out of school in order to return to school. Many factors that underlie the creation of school dropouts and children vulnerable to dropping out of school include economic factors, low parental care for children's education, and unfavorable living environment conditions. The program is carried out by means of observation, interviews, and documentation with the aim of getting accurate information and creating effective solutions to all the problems faced by foster siblings. The results obtained, the impact is very good for change both in terms of attitude and motivation. Foster siblings can return to school through the PKBM pathway, are more willing to express their thoughts, are more willing to appear in front of the general public, and are more motivated to study harder.
\end{abstract}

Keywords: Assistance, Foster Sister, drop out, Campus Social Responsibility

\section{PENDAHULUAN}

Pemerintah kota surabaya melalui dinas sosial telah bersinergi dengan beberapa perguruan tinggi baik negeri maupun swasta di surabaya untuk membantu penyelesaian permasalahan anak putus sekolah dan rentan 
putus sekolah melalui program Campus Social Responsibility (CSR). Program yang telah di mulai sejak 2014 menjadi alternatif dan mempunyai misi yang sangat mulia dengan tujuan mempercepat terpecahkannya permasalahan anak putus sekolah dan rentan putus sekolah dengan misi utama yaitu dilakukannya pendampingan dan pemberian bantuan baik materiil ataupun tenaga bagi anak usia sekolah oleh mahasiswa.

Mahasiswa mempunyai tiga peranan penting dalam masyarakat yaitu sebagai agen perubahan (agen of change), kontrol sosial (social control), generasi penerus (iron stock) yang harus berjuang terhadap perubahan menuju perbaikan dibidang sosial kemasyarakatatan (Istichomaharani \& Habibah, 2016). Sinergitas yang seimbang antara perguruan tinggi, masyarakat, dan pemerintah untuk saling bekerjasama sangat diperlukan. Sehingga mahasiswa sangatlah efektif untuk dilibatkan dalam segala kegiatan sosial khususnya pendampingan anak putus sekolah dan rentan putus sekolah.

Penyebab utama anak putus sekolah secara umum yaitu kondisi ekonomi keluarga yang kurang mendukung, faktor lingkungan, dan kondisi dalam diri setiap individu. Sementara perilakunya cenderung merujuk pada suatu perbuatan yang bersifat negatif (Rahmad, 2016). Faktor perhatian orang tua juga menjadi paling dominan ditunjukkan berdasarkan nilai varience explained tertinggi sebesar $39,95 \%$ dan varience explained terendah 17,014 \% (Dewi, Zukhri, \& Dunia, 2014)

Perbuatan negatif juga seringkali kita
jumpai dalam kehidupan sehari-hari
dianataranya yaitu mabuk-mabukan,
begadang di luar rumah, sering pulang
malam, dan mengkonsumsi narkoba. Sehingga, perlunya perhatian khusus bagi mereka baik oleh orang tua ataupun pemerintah agar tidak terjerumus pada perbuatan yang tidak baik.

Upaya mengatasi anak putus sekolah dapat dilakukan dengan sosialisasi, pemerataan program paket $\mathrm{A}, \mathrm{B}$, dan $\mathrm{C}$, pemerataan bantuan masyarakat, orang tua dan masyarakat memberikan motivasi kepada anak-anak untuk tetap bersekolah serta mengontrol pergaulan yang menyimpang (Windy, 2015). Upaya lain yang dapat dilakukan untuk mengatasi anak putus sekolah yaitu pelayanan sosial berupa bimbingan (Tamba, Krisnani, \& Gutama, 2014). Oleh karena itu, banyak sekali upaya yang dapat dilakukan baik oleh orang tua maupun masyarakat melalui program pendampingan maupun program program lainnya.

\section{METODE PELAKSANAAN}

Pelaksanaan program pendampingan adik asuh terdiri dari observasi, wawancara, dan dokumentasi. Kegiatan observasi dilakukan dengan tujuan untuk mendapatkan informasi-informasi yang dibutuhkan dan mengetahui latar belakang yang secara menyeluruh kondisi adik asuh dan keluarga. Kegiatan wawancara dilakukan agar dapat diketahui lebih dalam pokok permasalahan yang dialami adik asuh dan keluarga. Kegiatan dokumentasi dilakukan untuk mengumpulkan dokumen-dokumen dan segala bukti pendukung baik berupa foto, video, maupun data penting.

\section{HASIL DAN PEMBAHASAN}

Observasi lapangan dilakukan pada awal program CSR dengan tujuan untuk mengenali kondisi sebenarnya adik asuh baik dari segi lingkungan masyarakat sekitar dan lingkungan keluarga. Pada kegiatan tersebut, keluarga sangat menyambut baik kedatangan kakak asuh yang bertujuan untuk melakukan pendekatan persuasif adik asuh dengan kakak asuh serta mengidentifikasi segala permasalahan yang ada pada adik asuh. 

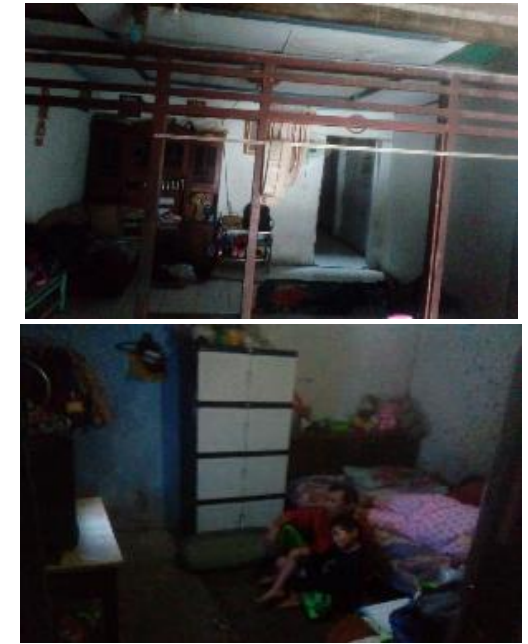

Gambar 1. Kondisi rumah adik asuh

\section{Permasalahan yang muncul} berdasarkan observasi lapangan antara lain: (1) Jumlah keluarga terdiri dari sembilan orang yaitu ayah, ibu, satu anak perempuan, dan enam anak laki-laki; (2) kondisi rumah sangat sederhana dan kurang proporsional karena ditempati oleh sembilan orang; (3) Kondisi lingkungan sekitar kurang mendukung karena terletak pada hunian kumuh dan kelompok menengah kebawah; (4) Rata-rata berstatus putus sekolah karena kondisi ekonomi keluarga yang kurang mampu; (5) Kondisi adik asuh yang putus sekolah sering mengamen untuk mendapatkan uang tambahan dan membantu pemenuhan kebutuhan sehari-hari; (6) kurangnya perhatian orang tua terhadap anaknya. Berdasarkan permasalahan permasalahan yang didapatkan, peneliti fokus pada pengembalian adik asuh untuk kembali bersekolah dan mengembangkan minat bakatnya baik secara akademis maupun non akademis.

Selanjutnya dilakukan perencanaan program kegiatan sebagai upaya pemecahan masalah yang di hadapi oleh adik asuh antara lain: (1) pengurusan Surat Keterangan Tidak Mampu (SKTM); (2) pendaftaran sekolah di PKBM MERCU BUANA;
Pengikutsertaaan adik asuh dalam program "Kampung Lali Gadget", (4) pengikutsertaan adik asuh pada kegiatan kreasi minat bakat di Universitas PGRI Adi Buana Surabaya pada acara orientasi mahasiswa baru; (5) kegiatan bimbingan belajar; (6) pemantauan perkembangan adik asuh secara berkelanjutan. (7) Evaluasi Pendampingan oleh Dinas Sosial Kota Surabaya.

SKTM digunakan sebagai syarat untuk pengurusan sekolah kejar paket. Pengurusan SKTM diawali dengan melakukan pengurusan surat pengantar ke RT/RW kemudian dilanjutkan pengurusannya ke kelurahan tandes dengan melampirkan beberapa persyaratan yaitu Pengantar RT/RW, kartu keluarga, dan foto copy Kartu Tanda Penduduk (KTP) kedua orang tua.
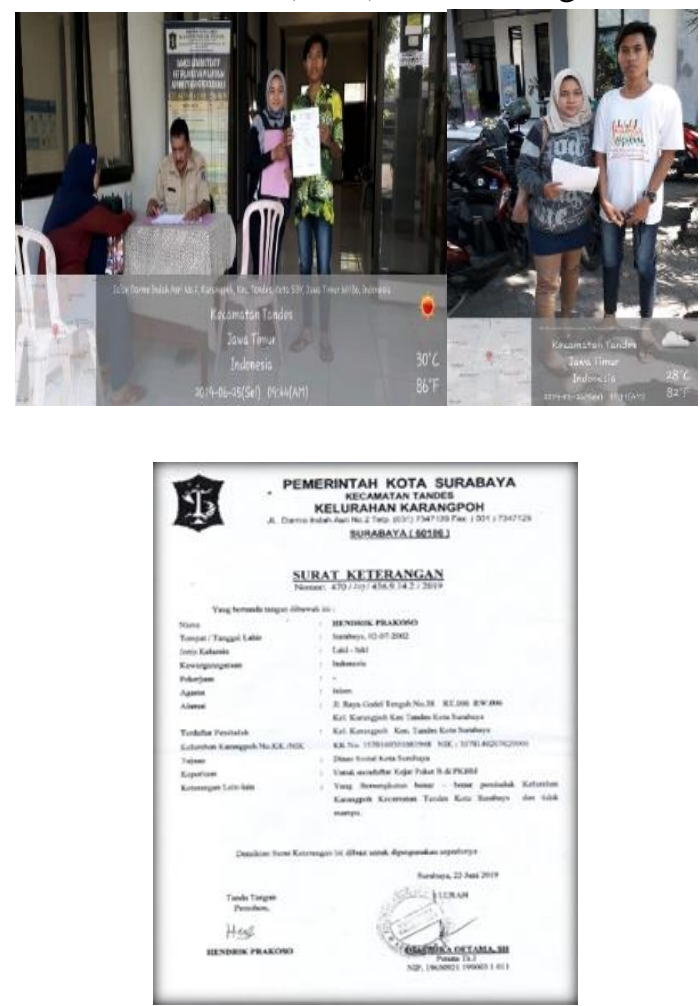

Gambar 2. Pengurusan SKTM di Kelurahan Tandes

Program Kegiatan Belajar Masyarakat (PKBM) merupakan lembaga bentukan masyarakat yang bergerak dalam bidang 
pendidikan dan menjadi solusi bagi masyarakat untuk melanjutkan program pendidikan. Dalam hal ini, adik asuh sangat antusias untuk segera mendaftar karena telah lama tidak berada pada bangku sekolah. Selain itu tidak adanya biaya yang dibebankan menjadi motivasi sendiri karena sepenuhnya dibiayai oleh Dinas Sosial Kota Surabaya. Pendaftaran PKBM adik asuh dilakukan dengan mempersiapkan beberapa syarat yang di butuhkan yaitu foto copy ijasah terakhir, foto copy kartu keluarga, dan mengisi formulir pendaftaran. Adapun kelengkapan lainnya yang perlu disiapkan yaitu past foto, foto copy raport, surat keterangan tidak mampu yang pengurusannya sepenuhnya di dampingi oleh kakak asuh.

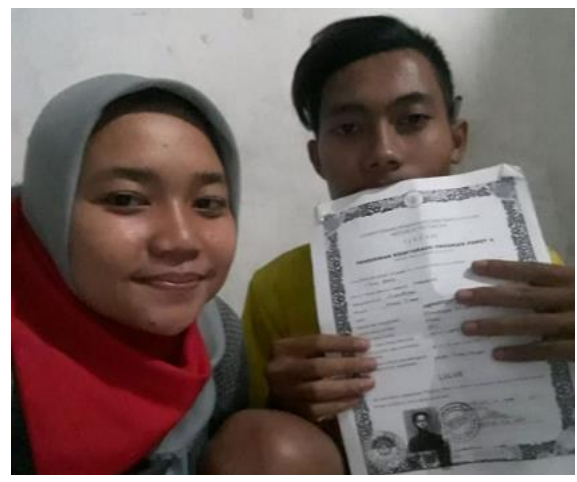

Gambar 3. Persiapan persyaratan pendaftaraan PKBM

Adik asuh didampingi kakak asuh untuk melakukan pendaftaran pada PKBM MERCUBUANA Surabaya yang dilakukan pada tanggal 13 Agustus 2019 dan telah diumumkan penerimaannya secara langsung dan dihimbau agar segera mempersiapkan segala yang dibutuhkan untuk sekolah.

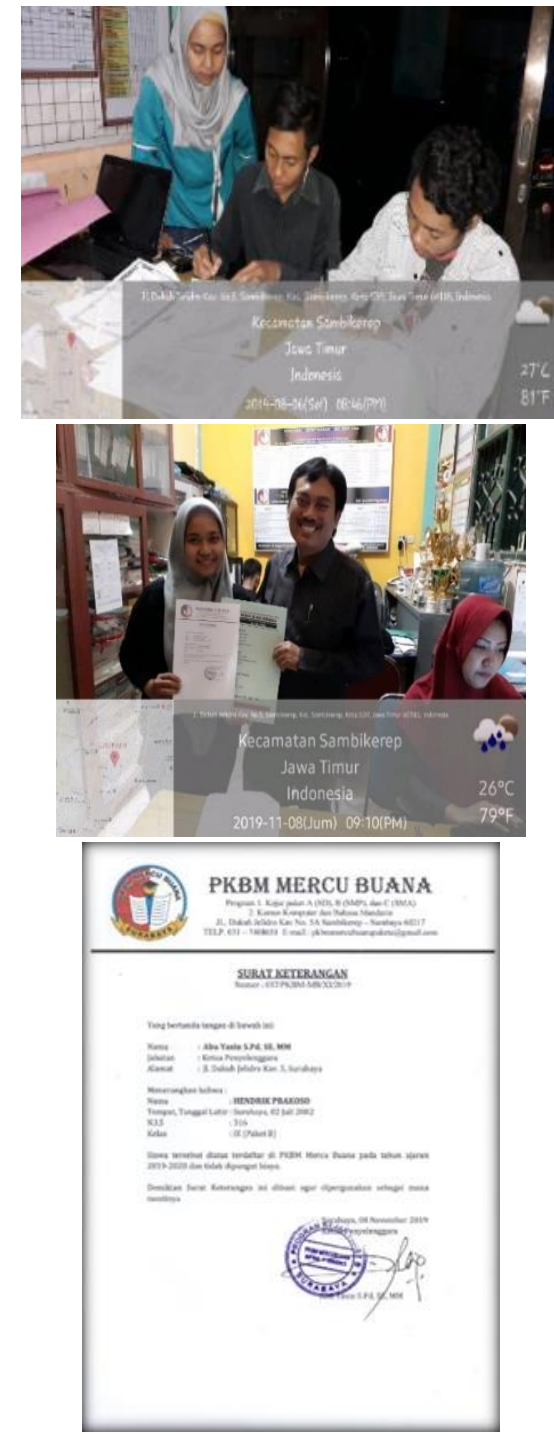

Gambar 4. Proses pendaftaran di PKBM MERCUBUANA Surabaya dan penyerahan bukti tidak adanya pungutan biaya

Program lain yang menunjang pengembangan karakter adik asuh, kakak asuh mengikutsertakan pada program "Kampung Lali Gadget" yang diadakan oleh pemerintah desa Pagerngumbuk kota Sidoarjo secara rutin setiap satu minggu sekali dengan tujuan pengembangan karakter serta menambah wawasan berkaitan pentingnya penggunaan gadjet sesuai dengan kebutuhan. Selain itu, banyak perubahan yang terjadi pada adik asuh yaitu mulai 
nyaman dalam bersosialisasi dengan teman sebayanya yang baru dikenal serta meningkatnya kemampuan komunikasi adik asuh dan tidak lagi malu.

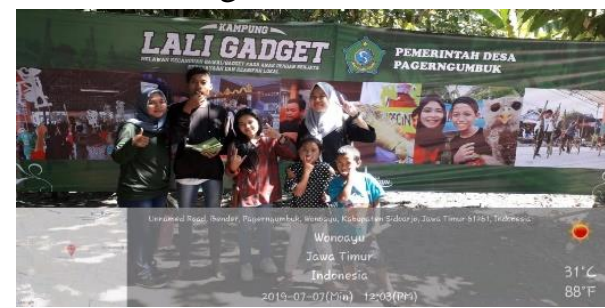

Gambar 5. Partisipasi dalam kegiatan "Kampung Lali Gadjet"

Kegiatan lain yang dilakukan kakak asuh untuk mengembangkan bakat serta kepercayaan diri adik asuh dengan cara mengikutsertakan adik asuh dalam kegiatan Pengenalan Kehidupan Kampus bagi Mahasiswa Baru (PKKMB) Universitas PGRI Adi Buana Surabaya. Salah satu bentuk keterlibatannya yaitu dengan ikut berpartisipasi langsung menampilkan musikalisasi puisi di hadapan seluruh mahasiswa baru Universitas PGRI Adi Buana Surabaya dan berkolaborasi dengan Unit Kegiatan Mahasiswa (UKM) Peduli Sosial. Respon adik asuh sangat senang dan termotivasi untuk ingin selalu terlibat dalam segala kegiatan luar sekolah.

Kemampuan akademik adik asuh juga menjadi perhatian penting, tidak hanya terpusat pada pengembangan kemampuan non akademik. Pendampingan kegiatan belajar di rumah juga dilakukan agar adik asuh termotivasi untuk belajar dan kakak asuh menjadikan dirinya sebagai fasilitator yang baik. Hal tersebut berdampak positif ditunjukkan dengan adanya partisipasi aktif oleh adik asuh sehingga semakin hari antusiasme semakin meningkat dalam kegiatan belajar dirumah.

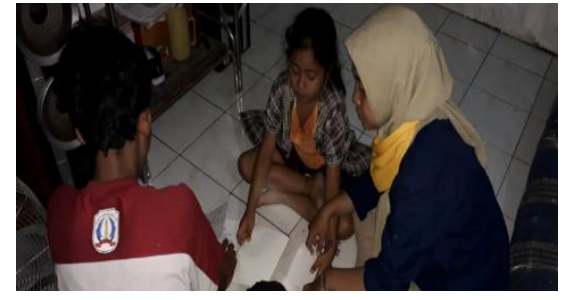

Gambar 6. Pendampingan kegiatan belajar mandiri dirumah

Evaluasi kegiatan pendampingan adik asuh menjadi sangat penting. Kegiatan tersebut dilakukan oleh Dinas Sosial kota Surabaya dan dosen pembimbing secara berkala. Segala permasalahan yang muncul di berikan solusi yang efektif agar pelaksanaan program pendampingan dapat berjalan dengan baik dan sesuai dengan perencanaan. Dinas sosial kota surabaya selalu memfasilitasi baik secara materiil maupun moril dengan memberikan rekomendasirekomendasi sampai dengan pemberian bantuan finansial. Hal tersebut memberikan motivasi tersendiri bagi kakak asuh untuk lebih aktif melakukan kegiatan pendampingan. Konsistensi pendampingan kakak asuh selalu ditekankan oleh Dinas Sosial kota

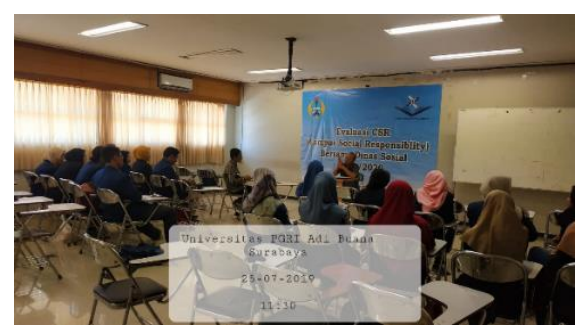

Gambar 7. Evaluasi bersama

Pelaksanaan Pendampingan oleh Dinas Sosial Kota Surabaya

\section{KESIMPULAN}

Program Campus Social Responsibility (CSR) Dinas Sosial Kota Surabaya merupakan program yang sangat baik dan menarik karena menjadi alternatif solusi terbaik dalam mengurangi jumlah anak putus 
sekolah dan rentan putus sekolah di kota Surabaya serta memberikan pengalaman belajar pada mahasiswa untuk membangkitkan rasa kepedulian sosial terhadap masyarakat sekitar dan memberikan pengalaman yang tidak didapatkan pada kegiatan perkuliahan. Sinergitas antara lembaga pendidikan tinggi dan pemerintah kota surabaya dalam hal ini diwakili oleh Dinas Sosial kota surabaya sangatlah penting untuk dilakukan agar segala permasalahan sosial yang ada di kota surabaya khususnya permasalahan anak putus sekolah dan rentan putus sekolah dapat terselesaikan.

Faktor yang mengakibatkan anak putus sekolah dan rentan putus sekolah dilatar belakangi oleh faktor ekonomi, rendahnya kepedulian orang tua terhadap pendidikan anak, dan lingkungan sekitar tempat tinggal yang buruk. Ketika program pendampingan adik asuh dilakukan, antusias masyarakat sangat besar dan orang tua berharap anaknya dapat kembali bersekolah.

Program yang direncanakan oleh kakak asuh sepenuhnya berjalan dengan baik dan berdampak positif terhadap perubahanperubahan baik dari segi sikap serta motivasi yang ada pada adik asuh. Hal tersebut terlihat dari perkembangan kemampuan bersosialisasi dengan masyarakat serta perubahan motivasi dari hari ke hari yang muncul untuk semakin giat belajar. Tidak hanya itu, monitoring adik asuh secara berkala juga menjadi hal penting agar tewujudnya konsistensi terhadap perubahanperubahan yang dialami oleh adik asuh.

\section{REFERENSI}

Dewi, N. A. K., Zukhri, A., \& Dunia, I. K. (2014). Analisis Faktor-Faktor Penyebab Anak Putus Sekolah 2012 / 2013. Jurnal Juruan Pendidikan Ekonomi.

Istichomaharani, I. S., \& Habibah, S. S. (2016). Mewujudkan Peran Mahasiswa Sebagai "Agent of Change, Social Control, dan Iron Stock." Pengintegrasian Nilai Karakter Dalam Pembelajaran Kreatif Di Era Masyarakat Ekonomi ASEAN.

Rahmad, M. (2016). Perilaku Sosial Anak Putus Sekolah. Jurnal Equilibrium Pendidikan Sosiologi.

Tamba, E. M., Krisnani, H., \& Gutama, A. S. (2014). Pelayanan Sosial Bagi Remaja Putus Sekolah. Share: Social Work Journal. https://doi.org/10.24198/share.v4i2.130 77

Windy, M. (2015). Studi Tentang Penyebab Anak Putus Sekolah Pada Masyarakat Nelayan Desa Ogomoli Kecamatan Galang Kabupaten Tolitoli. Edu Civic. 